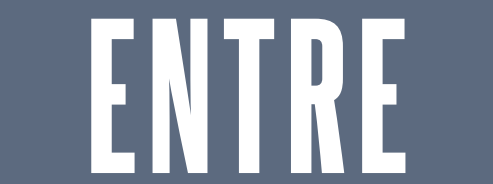

LIBROS

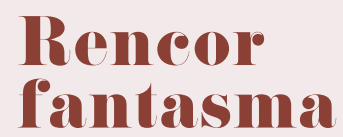

Novela

\section{Roberto BG}

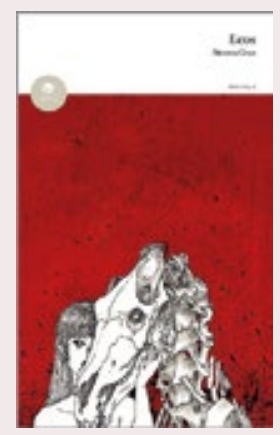

\section{Atenea Cruz, \\ Ecos, México, Feta, 2017, 108 pp.}

o cargué en mis brazos. Salimos. Me encaminé hacia el lago en la oscuridad. Estábamos solos. Cuando el agua me llegó a la cintura me detuve. Lo empujé hacia el fondo tanto como mis manos me lo permitieron. Al principio el bosque repitió como un quejido el chapoteo del agua. Se levantó un barullo de ecos asustados. Luego todo calló. Tuve frío. Y de pronto supe que ya no estaba soñando." En Ecos, de Atenea Cruz (Durango, 1984), todo comienza con un asesinato. Celia Santana, la protagonista de la novela, decide ahogar en un río cercano a su casa a su propio hijo, que padece de labio leporino y paladar hendido. Un bebé al cual aborrece, no solo por su deformidad física sino también porque condensa y representa todo aquello que la protagonista detesta de su vida: su rutina insoportable, la mediocridad de su esposo ("un soldado joven, sin privilegios"), el castigo que sufre por su pasado turbio (un despertar sexual rebelde y un aborto provocado por ella misma) y su problemática concepción de lo que significa ser madre (dados los conflictos que tuvo con la suya). Lo interesante del libro es que este comienzo en realidad es el final de los acontecimientos. Lo que leemos en los capítulos subsecuentes son los hechos que llevaron al desenlace dramático. Todo se articula muy inteligentemente mediante una estructura narrativa fragmentada dividida en tres partes, a la manera de las tres llamadas previas al inicio de una obra de teatro o de un espectáculo circense. En este sentido, la novela resulta poco convencional, en tanto que conjuga un estilo fragmentario, una capitulación en forma de cuenta regresiva, una narrativa no lineal $y$ un repertorio de voces narrativas múltiples que la vuelven, en su brevedad, una propuesta decididamente experimental y audaz.

Atenea Cruz, además de ser poeta y cuentista (con libros publicados y premios en ambos géneros literarios), ha presentado una primera novela con muchas resonancias literarias (un ejemplo en cuanto a tono y atmósfera: Amparo Dávila) y con un enorme trabajo de escritura y reescritura cuyo resultado ha sido un texto sintético, rotundo y polifacético. Hay varios temas que es posible vislumbrar con claridad desde la primera lectura: lo femenino, la maternidad, el rencor, el amor, la muerte. Todo desde una perspectiva oscura, ya que la historia

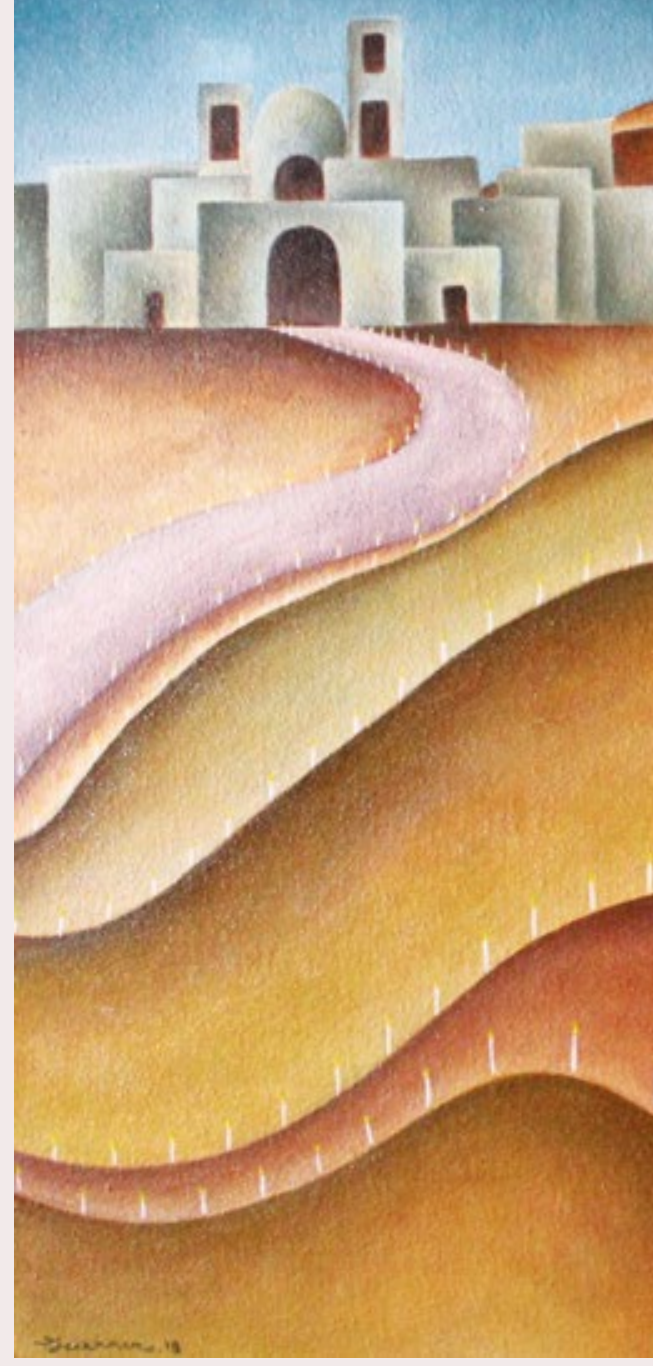

es contada como un cuento de fantasmas en el que poco a poco conocemos la raíz profunda y traumática del conflicto de los personajes involucrados: Celia, Bruno (su hijo), Raúl (su esposo), su madre, su abuela y Luis (su amante enano del circo).

A partir de ahí, la novela desarrolla tres ejes temáticos implicados entre sí, narrados en cada una de las partes. Primero, la imposibilidad de la relación entre sexos y su construcción como fantasía en la tensa relación interpersonal entre Celia y Raúl. Segundo, la familia como institución inestable y violenta en la 


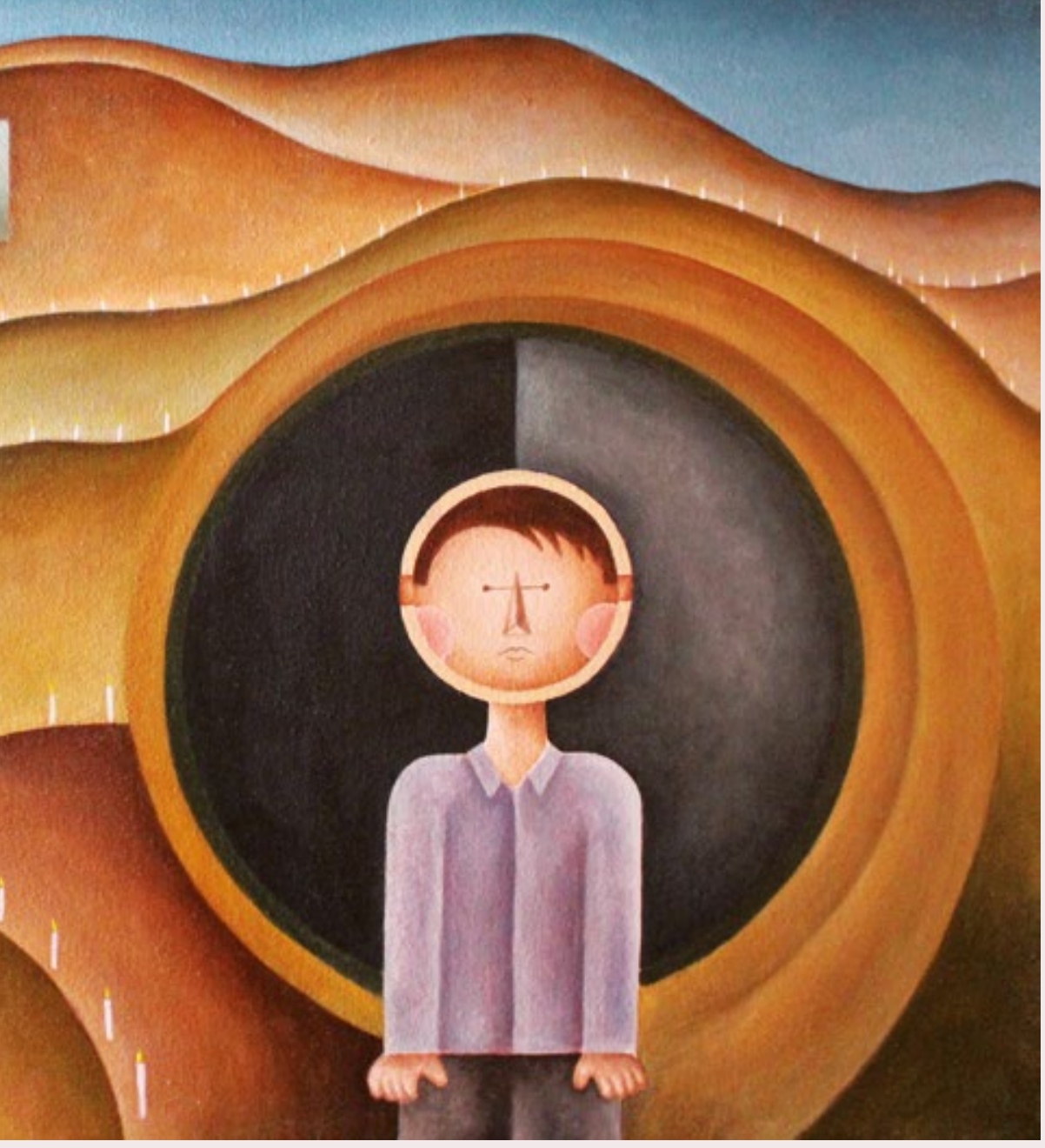

Javier Guerrero: Niño perdido (7 de diciembre)

que el pasado es una carga, y en la que las imposiciones morales y presiones sociales fragmentan historias de vida y pueden generar espirales de violencia interminables. Tercero, el despertar sexual como símbolo de liberación femenina frustrado. Porque, aunque Celia se emancipe del yugo de su madre a partir del ejercicio de su sexualidad a sus espaldas y como una forma de rebeldía, en realidad ella termina incorporándose a otras instancias de dominación en las cuales también debe cumplir un rol que estima carcelario y del que no puede salir más que exacerbando la violencia: de- ya que aunque no hay prácticamente una sola escena en la que se describa un encuentro sexual de forma explícita; lo que sí está presente de forma reiterada es la fantasía de la liberación ante la imposibilidad de conciliación entre los sexos, y cuyo clímax trágico se reitera como visión espectral para Raúl, quien presencia y escucha cómo se repite el episodio en que Celia sale de casa con su hijo en brazos para cruzar el bosque y ahogarlo en el río. Una fantasía que solo se satisface o se resuelve con la muerte.

Resulta notable que esta novela interrogue implacablemente uno de los valores menos cuestionados de nuestra sociedad: la idea generalizada de que el deseo mayor y la más grande aspiración de una mujer es la maternidad, porque aquí se representa como una pesadilla inenarrable. "Hay quien sostiene que, de acuerdo con su naturaleza, hay dos tipos principales de fantasmas: los que sufren y los que odian. Celia pertenecía a la segunda clase: rencor puro que horadaba la noche, en una suerte de gruñido bastante similar a los que emitía aquel hijo suyo que siempre detestó", enuncia el narrador. Esa es la razón por la que Celia aparece como un espectro enfurecido. Metáfora de la aversión soterrada por la maternidad sobre la que muy poco se ha escrito e indagado en un contexto como el mexicano (tan devoto de la figura de la madre). Una novela que revisa de forma incómoda y siniestra recovecos hasta ahora inexplorados de nuestro imaginario sexual y moral. Una novela, por lo tanto, necesaria. LPyH

Roberto BG (Aguascalientes, 1989) es ensayista y crítico literario. Actualmente es becario de la FLM. Su blog es: inconclusiones.com

jar de ser esposa y madre asesinando a su propio hijo.

Ecos es una novela donde la sexualidad femenina adquiere un protagonismo muy poco común, 